\title{
Effects of perceptions of information overload, noise and environmental demands on wellbeing and academic attainment
}

\author{
Hasah Alhenieidi ${ }^{1}$ and Andrew P Smith ${ }^{1}$, \\ ${ }^{1}$ Centre for Occupational and Health Psychology, School of Psychology, Cardiff University, \\ 63 Park Place, Cardiff CF10 3AS, \\ smithap@cardiff.ac.uk
}

\begin{abstract}
The present research considers components of information overload, which may have a negative impact on wellbeing and academic attainment. 179 university students completed a survey consisting of an information overload scale (IOS) and the wellbeing process questionnaire. Their academic attainment scores were also added to the database. The IOS scale also included questions relating to noise exposure. Both the noise scores and non-noise IOS scores were associated with greater negative wellbeing and lower positive wellbeing. There were no significant effects of noise or IOS scores on academic attainment. Wellbeing is predicted by a number of factors such as exposure to stressors, negative coping, social support and psychological capital. When these established factors were included in the analyses, the effects of noise and other aspects of IOS could be accounted for by exposure to other stressors and were no longer significant predictors of negative or positive wellbeing.
\end{abstract}

Keywords: information overload; noise; environmental demands; wellbeing; attainment

\section{Introduction}

\subsection{Mental Workload}

There has been considerable recent interest in models and applications of mental workload research [1, 2, 3,]. Mental workload has been examined using a variety of different methodologies [4, 5], and it has a long history in Psychology and related disciplines [6, 7]. It has been studied in both laboratory settings [8, 9] and the occupational context $[10,11]$, and a variety of measures of mental workload have been developed [12, 13, 14, 15, 16, 17]. These include physiological measures, task measures and self-assessment. Subjective report measures include the Subjective Workload Assessment Technique [4], the NASA Task Load Index [18], and the Workload Profile [19]. Recent research has shown that even single items measuring perceptions of workload are often highly correlated with longer scales and can predict the wellbeing of workers. Other approaches have examined specific aspects of workload, such as time pressure. This is a major component of the Karasek Job 
Demands scale, which has been shown to predict health and safety outcomes of workers [20].

\subsection{Effects of Noise}

One explanation of the negative effects of noise on performance is that the noise acts as an extra source of information that requires extra resources. These resources are then no longer available for the task being performed and performance is impaired $[21,22]$. Results from a number of studies [23, 24, 25, 26, 27] show that noise increases mental workload. Information overload has been studied extensively, and the aim of the present research was to examine the effects of information overload on the wellbeing and academic attainment of university students. Another specific aim, which forms the basis of the present paper, was to compare information overload due to noise with information overload from other sources.

\subsection{Information Overload}

The term "information overload" was mentioned by Toffler [28] in his book "Future Shock". Toffler described information overload as the difficulty a person may have in understanding an issue and making decisions because of the high presence of information. Information overload (IO) is the state of stress experienced when the amount of information given exceeds the limit of information user processing capacity [29]. This results in an impaired decision-making process, which can confuse the user and affect their overall work quality [30]. Several concepts, synonyms and related terms of information overload have been provided. These include cognitive overload, information fatigue syndrome, communication overload, sensory overload, knowledge overload, information anxiety, infobesity, information avoidance and social overload due to social networks services.

Numerous psychological and economic consequences of information overload result in severe implications at an individual and organizational level. Information overload is a form of cognitive barrier, whereby it blocks, limits or hampers the informationseeking process and causes frustration to the information user [31]. Research has revealed that information overload costs the US economy US\$900 billion annually [32], with resulting work stress triggering depression, anxiety, heart disease and high blood pressure [33]. However, more recent information overload implications are attributed to the evolving use of, and emerging reliability on, different internet activities, resulting in more distraction and excessive information flow. A heavy load of information confuses the user, affects their ability to set priorities, or makes prior information harder to recall [34]. Although the user can select where to focus their attention, paying attention is a cognitive limited resource that can be defective in overload situations [35]. Miller [36] hypothesized that processing performance of information is positively correlated with the received amount of information. When the information flow rises to the threshold, it leads to a cognitive decline in the ability to process the information.

Information overload in the workplace has been widely investigated, and its negative consequences on employees and companies have been documented. However, there is a lack of research about information overload on students and its 
association with wellbeing. There is also insufficient research on whether the large amount of information students receive from academic/scholarly activities, as well as non-scholarly/non-academic sources influence their wellbeing and academic performance.

\subsection{The Perceive Information Overload Scale}

There are many causes of information overload, and a questionnaire has been developed to measure exposure to these. The Perceived Information Overload Scale was developed by Misra and Stokols [37] and has good internal consistency $(\alpha=.86)$, and validity. The scale consists of 16-items that measures two subscales of information overload, environment-based and cyber-based information overload. The first part consists of nine items that explore the user's experience of information overload from cyber-based sources in the previous month, through a Likert scale of 5points $(0=$ never and $4=$ very often). Information users are asked about how often they felt overwhelmed to answer emails/ instant messages quickly; how often they felt that they had too many messages/emails or any social network notifications. The second part of the scale consists of seven items measuring participants' experience of the environment or place based on information overload in the last month. The questions explored include the workplace demands exceeding the user's ability to work, as well as a noisy and distracting work and the home environment. The items are summed to produce a total cyber-based information overload score and placebased information overload score. Although information overload is an indicator of stress, the findings of Misra and Stokols [37] indicate that the Perceived Information Overload Scale score and the Perceived Stress Scale score are not overlapping, which suggests that cyber-based and place-based information overload scales measure different concepts from perceived stress. Information overload and wellbeing have been investigated in five studies [38, 39, 40, 41, 42]. All the findings confirm the negative effect of information overload on wellbeing, although two studies demonstrated a positive effect if the internet connection is controlled.

\subsection{The Wellbeing Process}

Wellbeing is difficult to define and involves many different factors. The "wellbeing process model" we use is a holistic approach to wellbeing and attempts to provide a theoretical framework that could lead to the development of a questionnaire that could be useful in practice and policy. The initial research was based on the DemandsResources-Individual Effects (DRIVE) model, which was developed to conduct research in occupational stress [43, 44, 45, 46, 47]. This model included job characteristics, perceived stress, personal characteristics such as coping styles and negative outcomes (e.g. anxiety and depression). The next version of the model [ 48 , $49,50,51]$ included positive characteristics such as self-esteem, self-efficacy and optimism, and positive appraisals (e.g. job satisfaction) and outcomes (e.g. positive affect and happiness). Positive outcomes form the basis of a wide number of approaches to subjective wellbeing. However, it is important to include both positive and negative aspects of wellbeing as they involve different CNS mechanisms. 
One initial problem was that the wellbeing process model required measurement of many variables and that use of long scales which led to a questionnaire that was very lengthy and not very acceptable to the respondents. In order to remove this problem, short scales were developed, and these were found to be significantly correlated with the longer scales from which they were derived [52, 53, 54, 55, 57]. The questionnaire has been modified to use in research with students [57]. The outcome measures have also been increased to include academic attainment and perceptions of workload, work efficiency and course stress [58, 59]. The established predictors of student wellbeing are student stressors (e.g. too much academic work), social support, psychological capital (self-esteem, self-efficacy and optimism) and negative coping strategies (e.g. avoidance, wishful thinking and self-blame).

The initial aim of the present study was to examine whether noise-overload, information and overload from IT and media sources were associated with reduced wellbeing and poorer academic attainment. If these univariate analyses were significant, multi-variate analyses including the established predictors of wellbeing and attainment would be carried out, to determine whether noise and information overload had independent effects or whether they could be accounted for by other factors.

\section{Method}

\subsection{Participants}

One hundred and seventy-nine first-year psychology undergraduate students participated in the study as part of their course requirements. The majority of the sample population (91\%) were females. The age range was $18-50$ years; $89.9 \%$ were 18-21 years old. Course and exam scores were collected at the end of the semester using students' ID numbers.

\subsection{The Survey}

Questionnaires were completed electronically in a computer laboratory at the beginning of the academic year. Consent with the key features of voluntary participation, freedom to withdraw, anonymous databases, instructions, and debrief forms were provided at the start and the end of the study. The ethics committee at Cardiff University's School of Psychology approved the study. Data collection occurred in 2015.

\subsection{Measuring Instruments}

The survey included the Perceived Information Overload Scale (IOS) and the Student Wellbeing Process Questionnaire (WPQ). Attainment scores (examination and coursework marks) were obtained at the end of the first semester. 


\section{RESULTS}

\subsection{Analysis strategy}

Initial analyses examined the bivariate correlations between the IOS scores and the WPQ predictors and outcomes. Following this, regressions were carried out with the positive and negative wellbeing scores as dependent variables and the IOS scores and established predictors as independent variables.

\subsection{Correlations}

The three information overload scores were significantly correlated (IO due to noise/IO due to environment: $\mathrm{r}=0.55, \mathrm{p}<0.001$; IO due to noise/IO due to media: $\mathrm{r}$ $=0.30, \mathrm{p}<0.001$; IO due to environment $/ \mathrm{IO}$ due to media: $\mathrm{r}=0.34, \mathrm{p}<0.001)$. IO due to noise was negatively correlated with positive wellbeing $(r=-0.20, p=0.008)$ and positively correlated with negative wellbeing $(\mathrm{r}=0.26, \mathrm{p}<0.001)$. IO due to environmental factors was negatively correlated with positive wellbeing $(r=-0.21, p$ $=0.004)$ and positively correlated with negative wellbeing $(\mathrm{r}=0.25, \mathrm{p}=0.001)$. IO due to media was not significantly correlated with positive wellbeing but was correlated significantly with negative wellbeing $(\mathrm{r}=0.17, \mathrm{p}=0.02)$. The three IO measures were also positively correlated with exposure to stressors (IO noise: $\mathrm{r}=$ $0.25, \mathrm{p}=0.001$; IO environment: $\mathrm{r}=0.30, \mathrm{p}<0.001$; IO media: $\mathrm{r}=0.25, \mathrm{p}=0.001$ ) and negative coping (IO noise: $\mathrm{r}=0.23, \mathrm{p}=0.002$; $\mathrm{IO}$ environment: $\mathrm{r}=0.21, \mathrm{p}=$ 0.004; IO media: $r=0.23, p=0.002$ ). There were no significant correlations between the IO measures and the academic attainment scores (Exams and IO noise: $r=-0.08, p$ $=0.32$; Exams and $\mathrm{IO}$ due to media: $\mathrm{r}=0.00 \quad, \mathrm{p}=0.97$; Exams and $\mathrm{IO}$ environment: $r=-0.02, p=0.77$; Coursework and IO Noise: $r=-0.08, p=0.26$; Coursework and IO media: $r=0.00, p=0.97$; Coursework and IO environment: $r=-0.04, p=0.58$ ).

\subsection{Regressions}

Regressions were conducted with positive outcomes and negative outcomes as the dependent variables. The three IO scores and the established predictors from the WPQ (exposure to stressors, negative coping, positive personality and social support) were the independent variables. Negative outcomes were predicted by positive personality, exposure to stressors and negative coping but not by any of the information overload scores. These results are shown in Table 1. High stressor and negative coping scores were positively associated with negative wellbeing. In contrast, high positive personality (psychological capital) scores were negatively associated with negative wellbeing. 
Table 1: Predictors of negative outcomes

\begin{tabular}{lccccc}
\hline \multicolumn{1}{c}{ Model } & $\mathrm{B}$ & $\mathrm{SE}$ & $\mathrm{Beta}$ & $\mathrm{t}$ & $\mathrm{p}$ \\
\hline Constant & 37.288 & 4.952 & & 7.530 & .000 \\
IO Noise & .379 & .328 & .072 & 1.155 & .250 \\
IO Environment & .109 & .140 & .050 & .780 & .437 \\
IO Media & .020 & .094 & .012 & .216 & .830 \\
Stressors & .257 & .056 & .281 & 4.558 & .000 \\
Social Support & -.197 & .129 & -.083 & -1.533 & .127 \\
Negative Coping & .310 & .123 & .148 & 2.530 & .012 \\
Positive Personality & -.690 & .086 & -.461 & -7.981 & .000 \\
\hline
\end{tabular}

Positive outcomes were predicted by positive personality and social support but not by any of the IO measures. This is shown in Table 2.

Table 2: Predictors of positive outcomes

\begin{tabular}{llllll}
\hline Model & $\mathrm{B}$ & $\mathrm{S} . \mathrm{E}$. & Beta & $\mathrm{t}$ & $\mathrm{p}$ \\
\hline Constant & 2.955 & 1.704 & & 1.734 & .085 \\
IO Noise & -.055 & .113 & -.030 & -.487 & .627 \\
IO Environment & -.090 & .048 & -.116 & -1.873 & .063 \\
IO Media & .028 & .032 & .048 & .879 & .381 \\
Stressors & -.023 & .019 & -.071 & -1.179 & .240 \\
Social Support & .164 & .044 & .195 & 3.696 & .000 \\
Negative & -.020 & .042 & -.026 & -.465 & .642 \\
Coping & & & & & \\
Positive & .331 & .030 & .626 & 11.138 & .000 \\
Personality & & & & & \\
\hline
\end{tabular}




\section{Discussion}

The aim of the present study was to examine whether information overload was related to wellbeing and academic attainment. Information overload from noise was compared with information overload from media, such as the internet, and other demands due to work or leisure time activities. The three types of overload were correlated with each other and also with predictors of wellbeing such as stressors and negative coping. When established predictors of wellbeing were included in the regressions, there were no significant effects of any of the information overload variables for either negative or positive wellbeing. The established predictors of wellbeing had their usual associations with wellbeing, which gives one confidence in the information overload results.

\subsection{Effects of Noise}

Information overload due to noise was correlated positively with negative wellbeing and negatively with positive wellbeing. There were no significant correlations between information overload from noise and attainment measures. Other recent results [60] suggest that it is possible to demonstrate associations between noise exposure and wellbeing in a sample of office workers. This effect of noise remained significant when established predictors of wellbeing and environmental satisfaction were co-varied. The exposure of the office workers may be much higher than that of students, which could plausibly explain the different pattern of results. Further research investigating information overload in workers is now required to address this possibility.

\subsection{Information overload and wellbeing}

The pattern of results obtained here is similar to other findings that show that initial effects attributed to perceptions of information overload reflect associated factors. Alternatively, the negative results may reflect the fact that the students were only just starting at university when they completed the survey. Other results with student samples [61] shows that information overload from the internet is associated with poorer academic attainment, and it is possible that this effect takes time to develop.

4.3 Limitations The present study has a number of limitations. The first reflects the characteristics of the sample which consisted largely of female psychology students just starting university. A more representative sample of students would have been better, and it might have been wise to test them either before arriving at university or after they had been there for some time. It was not possible to remove these limitations in the present study due to logistic issues relating to who could be tested and when data collection could occur. Future research on this topic should also use other measures of noise, information overload, workload and wellbeing. The present research was restricted to an online survey which reduced the feasibility of objective measurement. Finally, it is difficult to identify causal mechanisms with a crosssectional design, and future research should be longitudinal, preferably involving interventions. 


\section{Conclusion}

The present research investigated whether components of information overload have a negative impact on wellbeing and academic attainment. A sample of first-year university students completed a survey consisting of an information overload scale (IOS) and the wellbeing process questionnaire. Their academic attainment scores were also available. The IOS scale included questions relating to the media, noise exposure and environmental demands. Both the noise scores and non-noise IOS scores were associated with greater negative wellbeing and lower positive wellbeing. There were no significant effects of noise or IOS scores on academic attainment. When the established predictors of wellbeing were included in the analyses, the effects of noise and other aspects of IOS could be accounted for by exposure to other stressors and were no longer significant predictors of negative or positive wellbeing. Further research with other samples, objective measurement and longitudinal designs is required to help explain such results and determine the impact on policy and practice. 


\section{References}

1. Longo, L., Leva M.C. (eds.) Human Mental Workload: Models and Applications. H-WORKLOAD 2017. Communications in Computer and Information Science, vol. 726, pp. 251-263. Springer, Cham. (2017)

2. Longo, L., Leva, M.C. (eds.) Human Mental Workload: Models and Applications. H-WORKLOAD 2018. Communications in Computer and Information Science. Springer, Cham. (2019).

3. Longo, L., Leva, M.C. (eds.) Human Mental Workload: Models and Applications. H-WORKLOAD 2019. Communications in Computer and Information Science. Springer, Cham. (2019).

4. Reid, G.B., Nygren, T.E.: The Subjective Workload Assessment Technique: A Scaling Procedure for Measuring Mental Workload, vol. 52. North-Holland (1988)

5. Stassen, H.G., Johannsen, G., Moray, N.: Internal representation, internal model, human performance model and mental workload. Automatica 26(4), 811--820 (1990)

6. De Waard, D.: The measurement of drivers' mental workload. The Traffic Research Centre VSC, University of Groningen (1996)

7. Hart, S.G.: Nasa-task load index (nasa-tlx); 20 years later. In: Human Factors and Ergonomics Society Annual Meeting. vol. 50. Sage Journals (2006)

8. Smith, A.P., Smith, K.: Effects of workload and time of day on performance and mood. In: Megaw, E. D. (ed.) Contemporary Ergonomics, pp. 497--502. Taylor \& Francis, London (1988)

9. Evans, M.S., Harborne, D., Smith A.P: Developing an objective indicator of fatigue: An alternative mobile version of the Psychomotor Vigilance Task (mPVT). Presented at: H-WORKLOAD 2018: International Symposium on Human Mental Workload: Models and Applications, Amsterdam, The Netherlands, 20-21 September 2018. Longo, L., Leva, M.C. (eds.): H-WORKLOAD 2018, CCIS 1012, pp. 147--159, 2019. Springer Nature Switzerland. (2019)

10.Smith, A.P., Smith, H.N.: Workload, fatigue and performance in the rail industry.In: Longo, L., Leva M.C. (eds.) Human Mental Workload: Models and Applications. H-WORKLOAD 2017. Communications in Computer and Information Science, vol. 726, pp. 251-263. Springer, Cham. (2017)

11.Fan, J., Smith, A.P.: Mental workload and other causes of different types of fatigue in rail staff. In: Longo, L., Leva, M.C. (eds.) Human Mental Workload: Models and Applications. H-WORKLOAD 2018. Communications in Computer and Information Science 1012, pp. 147-159. Springer, Cham. (2019).

12.Cortes Torres, C.C., Sampei, K., Sato, M., Raskar, R., Miki, N. : Workload Assessment with Eye Movement Monitoring Aided by Non-invasive and Unobtrusive Micro-fabricated Optical Sensors. Adjunct Proceedings of the 28th Annual ACM Symposium on User Interface Software \& Technology pp. 53-54 (2015).

13. Yoshida, Y., Ohwada, H., Mizoguchi, F., Iwasaki, H.: Classifying Cognitive Load and Driving Situation with Machine Learning. Int. J. Mach. Learn. Comput. 4(3), 210--215 (2014) 
14.Wilson, G.F., Eggemeier, T.F.: Mental workload measurement. In: Karwowski, W. (ed.) International Encyclopedia of Ergonomics and Human Factors (2nd ed.), vol. 1, chap. 167. Taylor \& Francis (2006)

15.Young, M.S., Stanton, N.A.: Mental workload. In: Stanton, N.A., Hedge, A., Brookhuis, K., Salas, E., Hendrick, H.W. (eds.) Handbook of Human Factors and Ergonomics Methods, chap. 39, pp. 1--9. CRC Press (2004)

16. Young, M.S., Stanton, N.A.: Mental workload: Theory, measurement, and application. In: Karwowski, W. (ed.) International encyclopedia of ergonomics and human factors, vol. 1, pp. 818--821. Taylor \& Francis, 2nd ed. (2006)

17. Moustafa, K., Saturnino, L., Longo, L.: Assessment of mental workload: a comparison of machine learning methods and subjective assessment techniques. In: 2017 1st International Symposium on Human Mental Workload: models and applications. vol. CCIS 726, pp. 30--50. Springer International Publishing (June 2017)

18. Hart, S.G., Staveland, L.E.: Development of NASA-TLX (Task Load Index): Results of Empirical and Theoretical Research. Adv. Psychol. 52(C), 139--183 (1988)

19. Tsang, P.S., Velazquez, V.L.: Diagnosticity and multidimensional subjective work- load ratings. Ergonomics. 39(3), 358--381 (1996)

20. Karasek Jr, R.A.: Job demands, job decision latitude, and mental strain: Implications for job redesign. Adm. Sci. Q. 285-308 (1979)

21. Smith, A.P.: A review of the effects of noise on human performance. Scandinavian Journal of Psychology, 30, 185 - 206 (1989)

22. Smith, A. P., Jones, D. M.: Noise and performance. In: Handbook of human performance, Vol.1: The physical environment. (eds) A. P. Smith \& D. M. Jones. London: Academic Press. Pp.1-28 (1992)

23. McNeer, R., Bennett, C., Dudaryk, R.: Intraoperative noise increases perceived task load and fatigue in anesthesiology residents: A simulation based study. Anesth Analg, 122(2), 512-525 (2016)

24. Rosen, M., Dietz, A., Lee, N., Wang, I-J., Markowitz, J., Wyskiel, M. et al.: Sensor-based measurement of critical care nursing workload: Unobtrusive measures of nursing activity complement traditional task and patient level indicators of workload to predict perceived exertion. Plos One, 13(10), e0204819 (2018)

25. Jahncke, H., Bjorkeholm, P., Marsh, J., Odelius, J., Sorqvist, P.: Office noise: Can headphones and masking sound attenuate distraction by background speech? Work, 55(3), 505-513 (2016)

26. Gao, J., Liu, S., Feng, Q., Zhang, X., Zhang, J., Jiang, M. et al.: Quantitative evaluations of the effects of noise on mental workloads based on pupil dilation during laparoscopic surgery. Am Surg, 84 (12), 1951-1956 (2018)

27. Becker, A., Warm, J., Dember, W., Hancock, P.: Effects of jet engine noise and performance feedback on perceived workload in a monitoring task. Int J Aviat Psychol, 5 (1), 49-62 (1995)

28. Toffler, A.: Future shock. New York: Bantam Books (1970)

29. Eppler, M.J., Mengis, J.: The concept of information overload: A review of literature from organization science, accounting, marketing, and related disciplines. The Information Society, 20(5), 325-344 (2004) 
30. Chewning Jr, E. G., Harrell, A. M.: The effect of information load on decision makers' cue utilization levels and decision quality in a financial distress decision task. Accounting, Organizations and Society, 15(6), 527-542 (2009)

31. Savolainen, I., Kaakinen, M., Sirola, A., Oksanen, A.: Addictive behaviors and psychological distress among adolescents and emerging adults: A mediating role of peer group identification. Addictive Behaviors Reports, 7, 75-81 (2018)

32. Spira, J.,Burke, C.: Intel's war on information overload: Case study. Basex. http://iorgforum.org/wp-content/uploads/2011/06/IntelWarIO.BasexReport1.pdf (2009)

33. Guarinoni, M., Belin, A., Oulès, L., Graveling, R., Crawford, J., Lietzmann, J., Kaminskas, K. A.: Occupational health concerns: Stress-related and psychological problems associated with work. Brussels: European Parliament's Committee on Employment and Social Affairs (2013)

34. Schick, A. G., Gorden, L. A.,Haka, S.: Information overload: A temporal approach. Accounting Organizations and Society, 15(3), 199-220 (1990)

35. McLeod,S.A.: Selective attention. http://www.simplypsychology.org/attentionmodels.html (2008)

36. Miller, G.A.: The magical number seven, plus or minus two: Some limits on our capacity for processing information. Psychological Review, 63(2), 81-97 (1956)

37. Misra, S., Stokols, D.: Psychological and health outcomes of perceived information overload. Environment and Behavior, 44(6), 737-759 (2011)

38. LaRose, R., Connolly, R., Lee, H., Li, K., Hales,K.D.: Connection Overload? A Cross Cultural Study of the Consequences of Social Media Connection, Information Systems Management, 31:1, 59-73 (2014)

39. Lee, H., Connolly, R., Li, K., Hales, K., LaRose,R.: Impacts of social media connection demands: A study of Irish college students. Available from https://aisel.aisnet.org/amcis2013/SocialTechnicalIssues/GeneralPresentations/6/ (2013)

40. Saunders, C., Wiener, M., Klett, S., Sprenger, S.: The impact of mental representations on ICT-Related overload in the use of mobile phones. Journal of Management Information Systems, 34(3), 803-825 (2017)

41. Sonnentag, S.: Being Permanently Online and Being Permanently Connected at Work: A Demands-Resources Perspective. In Permanently Online, Permanently Connected (pp. 258-267). Routledge (2017)

42. Swar, B., Hameed, T., Reychav, I. Information overload, psychological ill-being, and behavioral intention to continue online healthcare information search. Computers in Human Behavior, 70, 416-425 (2017)

43. Mark, G.M., Smith, A.P.: Stress models: A review and suggested new direction. In J. Houdmont \& S. Leka (Eds.), Occupational health psychology: European perspectives on research, education and practice Nottingham: Nottingham University Press. Pp. 111-144 (2008)

44. Mark, G., Smith, A.P. Effects of occupational stress, job characteristics, coping and attributional style on the mental health and job satisfaction of university employees. Anxiety, Stress and Coping, 25, 63-78 (2011)

45. Mark, G., Smith, A.P. Occupational stress, job characteristics, coping and mental health of nurses. British Journal of Health Psychology, 17, 505-521 (2012) 
46. Mark, G., Smith, A.P. A qualitative study of stress in university staff. Advances in Social Sciences Research Journal, 5(2):238-247 (2018)

47. Mark, G, Smith, A.P. Coping and its relation to gender, anxiety, depression, fatigue, cognitive difficulties and somatic symptoms. Journal of Education, Society and Behavioral Science, 25(4), 1-22 (2018)

48. Smith, A.P.: A holistic approach to stress and wellbeing. Occupational Health (At Work), 7(4), 34-35 (2011)

49. Smith, A.P., Wadsworth, E.: A holistic approach to stress and wellbeing. Part 5: what is a good job?, Occupational Health (At Work), 8(4), 25-27 (2011)

50. Smith, A.P.,Wadsworth, E.J.K., Chaplin, K., Allen, P.H.,Mark, G.: The relationship between work/wellbeing and improved health and wellbeing. Leicester: IOSH (2011)

51. Wadsworth, E.J.K., Chaplin, K., Allen, P.H., Smith, A.P.: What is a Good Job? Current Perspectives on Work and Improved Health and Wellbeing. The Open Health \& Safety Journal, 2, 9-15 (2010)

52. Williams, G.M., Smith, A.P.: Using single-item measures to examine the relationships between work, personality, and wellbeing in the workplace. Psychology: Special Edition on Positive Psychology, 7, 753-767 (2016)

53. Williams, G.M., Smith, A.P. A holistic approach to stress and wellbeing. Part 6: The Wellbeing Process Questionnaire (WPQ Short Form). Occupational Health (At Work), 9(1), 29-31 (2012)

54. Williams, G.M., Smith, A.P.: Diagnostic validity of the anxiety and depression questions from the Wellbeing Process Questionnaire. Journal of Clinical and Translational Research, 10, (2018)

55. Williams, G.M., Pendlebury, H., Smith, A.P.: Stress and wellbeing of nurses: An Investigation using the Demands-Resources- Individual Effects (DRIVE) model and Wellbeing Process Questionnaire (WPQ). Jacobs Journal of Depression and Anxiety, 1:1-8. (2017).

56. Williams, G., Thomas, K., Smith, A.P.: Stress and wellbeing of university staff: An investigation using the Demands-Resources- Individual Effects (DRIVE) model and Wellbeing Process Questionnaire (WPQ). Psychology, 8, 1919-1940 (2017)

57. Williams, G.M., Pendlebury, H., Thomas, K., Smith, A.P.: The student wellbeing process questionnaire (Student WPQ). Psychology, 8, 1748-1761 (2017)

58. Smith, A.P., Firman, K.L.: Associations between the wellbeing process and academic outcomes. Journal of Education, Society and Behavioural Science, 32(4), 1-10 (2019)

59. Smith, A.P.: Student Workload, Wellbeing and Academic Attainment. In L. Longo and M.C. Leva (eds) H-WORKLOAD 2019. Communications in Computer and Information Science 1107. (C) Springer Nature Switzerland AG. https://doi.org/10.1007/978-3-030-32423-0_3 Print ISBN 978-3-030-32422-3. Online ISBN 978-3-030-32423-0 (2019)

60. Langer, J., Taylour, J., Smith, A.P. (in press). Noise exposure, satisfaction with the working environment, and the wellbeing process. ICBEN 2020.

61. Smith, A.P., Izadvar, S. Effects of the internet, other media and study time on wellbeing and academic attainment of university students. International Journal of Education Humanities and Social Science, Vol. 3, No. 02, 1-13, (2020) 